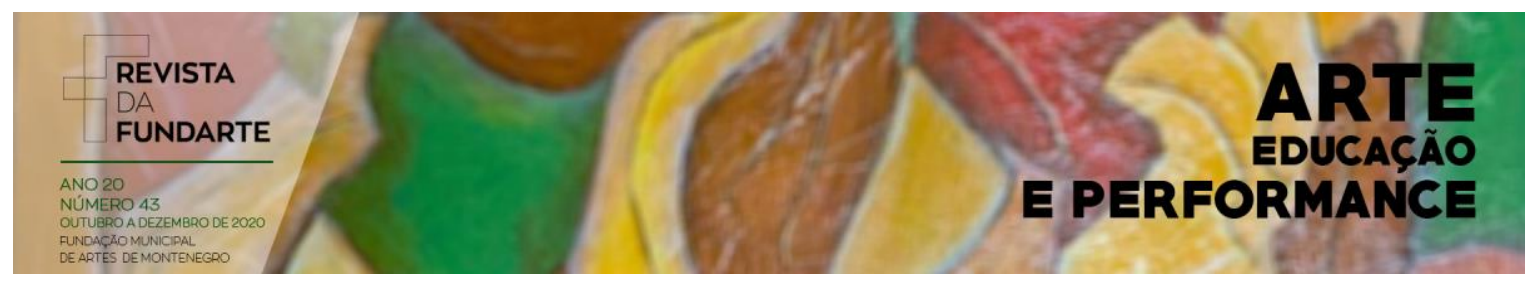

\title{
EXPERIÊNCIA ARTÍSTICA NA FORMAÇÃO DOCENTE EM ARTES VISUAIS: UMA CARTOGRAFIA SOBRE OS PERCURSOS FORMATIVOS DE ESTUDANTES EM GRADUAÇÃO
}

\author{
Ana Carolina Ribeiro Nogueira
}

DOI: http://dx.doi.org/10.19179/2F2319-0868/2F735

NOGUEIRA, Ana Carolina Ribeiro. Experiência artística na formação docente em artes visuais: uma cartografia sobre os percursos formativos de estudantes em graduação. Revista da FUNDARTE. Montenegro, p.01-15, ano 20, no 43, outubro/dezembro de 2020.

Disponível em: http://.seer.fundarte.rs.gov.br/index.php/revistadafundarte/index $>20$ de dezembro de 2020. 


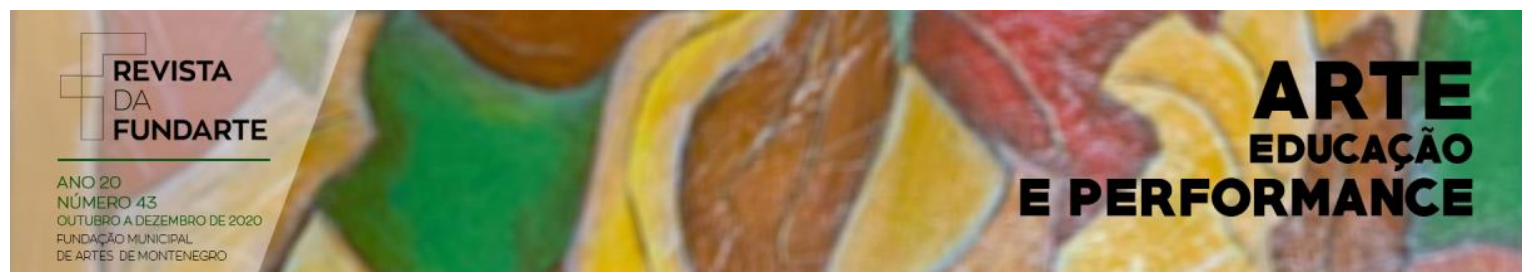

\title{
EXPERIÊNCIA ARTÍSTICA NA FORMAÇÃO DOCENTE EM ARTES VISUAIS: UMA CARTOGRAFIA SOBRE OS PERCURSOS FORMATIVOS DE ESTUDANTES EM GRADUAÇÃO
}

Ana Carolina Ribeiro Nogueira ${ }^{1}$

\begin{abstract}
Resumo: Este relato de experiência é parte de uma pesquisa na qual investiguei o lugar da experiência artística durante o percurso de formação de estudantes de graduação em Artes Visuais da Universidade do Estado de Santa Catarina. Procurei identificar conceitos e práticas relacionados a tal experiência, tentando compreender de que forma estes aspectos influenciam os percursos dos participantes desta pesquisa. Trabalhei com o método cartográfico a fim de compreender como os estudantes compõem e compreendem suas experiências durante o período de graduação. Aqui optei por apresentar duas partes da pesquisa que abordaram a relação dos estudantes com a universidade e com o curso de Artes Visuais como possibilidade de graduação e carreira profissional.
\end{abstract}

Palavras-chave: Artes Visuais; Formação universitária em Artes; Experiência artística.

\section{ARTISTIC EXPERIENCE IN VISUAL ARTS TEACHING TRAINING: A CARTOGRAPHY ABOUT AN UNDERGRADUATE STUDENT FORMATION JOURNEY}

\begin{abstract}
This experience report is part of a research in which I investigated the place of the artistic experience during the training course for undergraduate students in Visual Arts at Universidade Estadual de Santa Catarina. I tried to identify concepts and practices related to such experience, trying to understand how these aspects influence the pathways of the participants of this research. I worked with the cartographic method to understand how students compose and understand their experiences during the undergraduate period. Here I chose to present two parts of the research that addressed the students' relationship with the university and the Visual Arts course as a possibility of graduation and professional career.
\end{abstract}

Keywords: Visual Arts; University training in Arts; Artistic experience.

\footnotetext{
1 Professora, pesquisadora e artista. Doutoranda em Artes Visuais pela Universidade do Estado de Santa Catarina, na linha de pesquisa de Ensino das Artes Visuais e Mestra em Antropologia Social pela Universidade Federal de Santa Catarina (PPGAS/UFSC/2014). Graduada em Licenciatura em Artes Visuais pela Universidade do Estado de Santa Catarina (UDESC/CEART) e Pós-Graduada em Gestão Cultural pelo SENAC Santa Catarina (2011). Participa do Projeto de Pesquisa Paisagens Pedagógicas (UDESC-SC). É professora de Artes Visuais e atua no Ensino Fundamental da Rede Municipal de Educação de Florianópolis, SC. Desenvolve pesquisa com ênfase no Ensino das Artes Visuais, abordando questões de currículo.
}

NOGUEIRA, Ana Carolina Ribeiro. Experiência artística na formação docente em artes visuais: uma cartografia sobre os percursos formativos de estudantes em graduação. Revista da FUNDARTE. Montenegro, p.01-20, ano 20, no 43, outubro/dezembro de 2020.

Disponível em: http://.seer.fundarte.rs.gov.br/index.php/revistadafundarte/index> 20 de dezembro de 2020. 


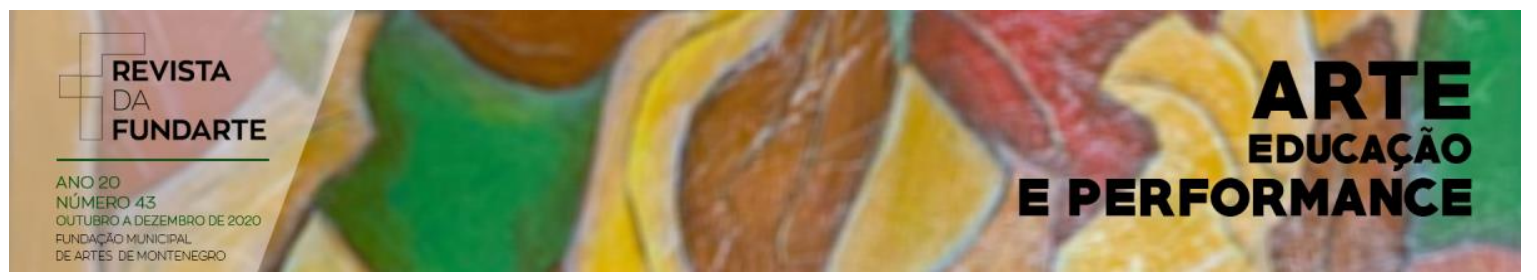

\section{A experiência na universidade em um curso de Artes Visuais}

O lugar da experiência artística na graduação em Artes Visuais é o problema de que trato nesta pesquisa. Experiências que se dão em distintas temporalidades e a partir das relações que os sujeitos estabelecem com o tempo, levando em consideração a atual conjuntura em que grande parte de nós, estudantes e professores, vivemos; quando tudo ao nosso redor se passa demasiadamente rápido, os estímulos são cada vez mais fugazes e os acontecimentos se dão de forma abrupta. Diante deste cenário, como tem acontecido a formação dos estudantes de graduação em Artes Visuais à sombra desta engrenagem acelerada e tarefeira?

A partir de entrevistas e conversas filmadas, provoquei os participantes a criarem mapas de percursos, no intuito de discutir questões sobre o lugar da experiência artística com base no reconhecimento de rastros das memórias, desde o processo de escolha do curso até os últimos períodos de formação.

Para adentrarmos nestas questões, proponho pensarmos sobre o par conceitual experiência/sentido sugerido por Jorge Larrosa ${ }^{2}$ (2017, p. 25), que compreende a experiência como algo que "afeta de algum modo, produz alguns afetos, inscreve algumas marcas, deixa alguns vestígios, alguns efeitos". Vale lembrar que a experiência para o referido autor possui uma temporalidade relativa, podendo ocorrer, tanto de um dia para outro, como transcorrer durante um longo período de tempo. Para ele (2017, p. 28), um dos principais elementos que o conceito de experiência abarca é "a sua capacidade de formação ou de transformação", de modo que, ao nos acontecer, nos afetar, ou "nos passar", a experiência forma e transforma o sujeito que a ela está exposto.

Meu ponto de partida é o atual contexto de formação, que se desenvolve concomitantemente às transformações políticas, econômicas e sociais, as quais,

\footnotetext{
2 O autor trata mais especificamente deste tema no livro Tremores: escritos sobre experiência, de 2017 (cf. Referências).
}

NOGUEIRA, Ana Carolina Ribeiro. Experiência artística na formação docente em artes visuais: uma cartografia sobre os percursos formativos de estudantes em graduação. Revista da FUNDARTE. Montenegro, p.01-20, ano 20, no 43, outubro/dezembro de 2020.

Disponível em: http://.seer.fundarte.rs.gov.br/index.php/revistadafundarte/index> 20 de dezembro de 2020. 


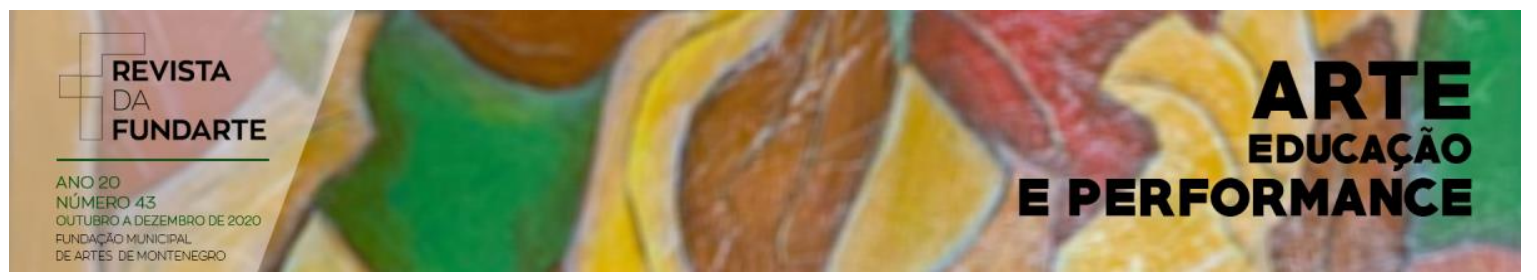

associadas a outros fatores, influenciariam diretamente as bases do funcionamento do processo formativo de estudantes graduandos. Minha hipótese, ao iniciar esta pesquisa, era de que esta dinâmica acelerada tem contribuído para empobrecer e até mesmo suprimir a possibilidade de experiências artísticas durante o processo formativo dos estudantes, especialmente dos licenciandos, que estariam submetidos a uma estrutura curricular mais densa e mais focada em aspectos teórico/pedagógicos e burocracias, do que os alunos de bacharelado.

Segundo minhas primeiras suposições, tal aceleração temporal somada a uma excessiva demanda de afazeres curriculares acarretaria em um processo de formação prolixo e apressado, no qual estudantes e professores estariam, na maior parte do tempo, cumprindo obrigações burocráticas e curriculares que suprimiriam o tempo para a prática e a experiência artística durante a realização das disciplinas. Isso acarreta no que tange à produção artística, uma formação imatura e com tendências mais teóricas do que práticas.

Por outro lado, apesar de serem estas as minhas suspeitas, saí a campo contando também com a possibilidade de que tais condições pudessem ser transformadas e subvertidas por alguns sujeitos que desafiam as estruturas curriculares e percorrem caminhos alternativos em busca de experiências artísticas durante o percurso formativo, a fim de satisfazerem suas expectativas em relação ao curso. Assim, por conta do tempo e da possibilidade de abrangência desta pesquisa, optei em convidar estudantes que, mesmo em meio ao frenesi e ao arrebatamento impostos pelas demandas institucionais, criaram alternativas para realizarem 0 curso, priorizando a experiência artística, procurando por atividades de monitoria em ateliês e/ou projetos coletivos e individuais, dentro ou fora da universidade, os quais possibilitam longos períodos de vivência com as linguagens artísticas com as quais atuam.

Minha primeira opção foi trabalhar apenas com estudantes do curso de licenciatura, mas ao perceber que alguns bacharelandos desenvolviam projetos

NOGUEIRA, Ana Carolina Ribeiro. Experiência artística na formação docente em artes visuais: uma cartografia sobre os percursos formativos de estudantes em graduação. Revista da FUNDARTE. Montenegro, p.01-20, ano 20, no 43, outubro/dezembro de 2020.

Disponível em: http://.seer.fundarte.rs.gov.br/index.php/revistadafundarte/index> 20 de dezembro de 2020. 


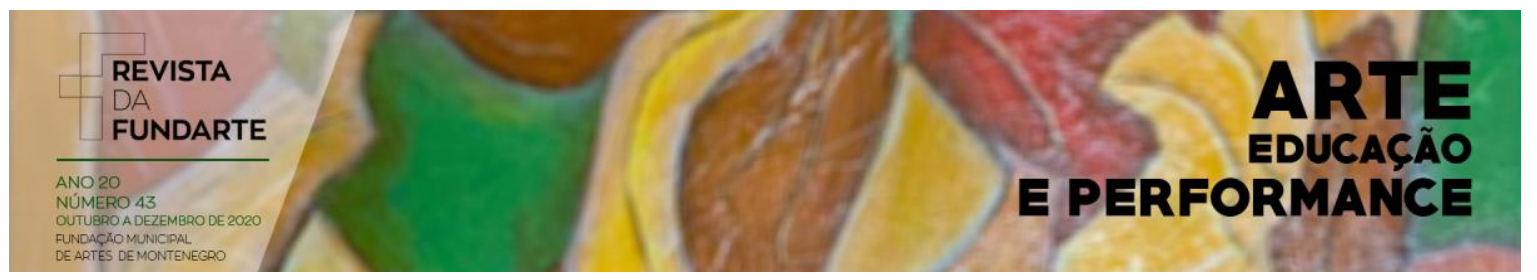

educacionais em formato de oficinas, ateliês livres, geodésicas ${ }^{3}$ e outros tipos de espaços de formação, optei também em convidar para a pesquisa estudantes com esse perfil. Sendo assim, este trabalho trata de investigar modos de produção de diferenças em trajetórias de constituição de artistas e professores de Artes Visuais durante seus processos de formação universitária.

As questões sobre tempo, velocidade, instrumentalização, prática e experiência no contexto de formação têm sido tema de pesquisa de autores como Jorge Larrosa (2017) e Célia Maria de Castro Almeida (2009), que são dois dos principais autores que eu trouxe para dialogarem nesta investigação, especificamente, sobre modos de produção e experiência artística durante o processo de graduação. Além de compreender que ambos os autores seguem linhas epistemológicas distintas, também levei em consideração que eles têm a experiência como mote de suas reflexões e pesquisas, mas fazem isso comentando ou traçando conexões entre conceitos de outros autores que foram precursores ao tratar da questão da experiência, como Walter Benjamin e Martin Heidegger. Deste modo, também achei importante trazer contribuições de um dos pioneiros nas investigações sobre a experiência no campo das artes: o filósofo John Dewey.

É importante apontar que as diferenças epistemológicas entre os autores são levadas em conta, e que o objetivo foi apresentar não apenas pontos em comum, mas também ideias divergentes, estabelecendo relações com as concepções dos estudantes que participaram desta pesquisa.

Ao propor, então, uma investigação sobre a experiência artística em processos de formação, elaborei as seguintes questões que norteiam este trabalho:

1. Os estudantes alegam falta de experiências artísticas no seu processo de

\footnotetext{
${ }^{3}$ A Geodésica Cultural Itinerante é um coletivo de arte colaborativa, composto por artistas de diversas áreas, que utiliza uma estrutura geodésica como dispositivo relacional itinerante. Possui o objetivo de ativar criativamente diferentes contextos e espaços públicos, visando à reinvenção de relações sociais, culturais e ambientais. São realizadas atividades de caráter transdisciplinar, como oficinas, conversas e ações artísticas que buscam a produção de sentido a partir da experiência. Disponível em: <https://www.udesc.br/ceart/fik/convidadosnacionais/geodesicaitinerante>. Acesso em: 9 nov. 2018.
}

NOGUEIRA, Ana Carolina Ribeiro. Experiência artística na formação docente em artes visuais: uma cartografia sobre os percursos formativos de estudantes em graduação. Revista da FUNDARTE. Montenegro, p.01-20, ano 20, № 43, outubro/dezembro de 2020.

Disponível em: http://.seer.fundarte.rs.gov.br/index.php/revistadafundarte/index> 20 de dezembro de 2020. 


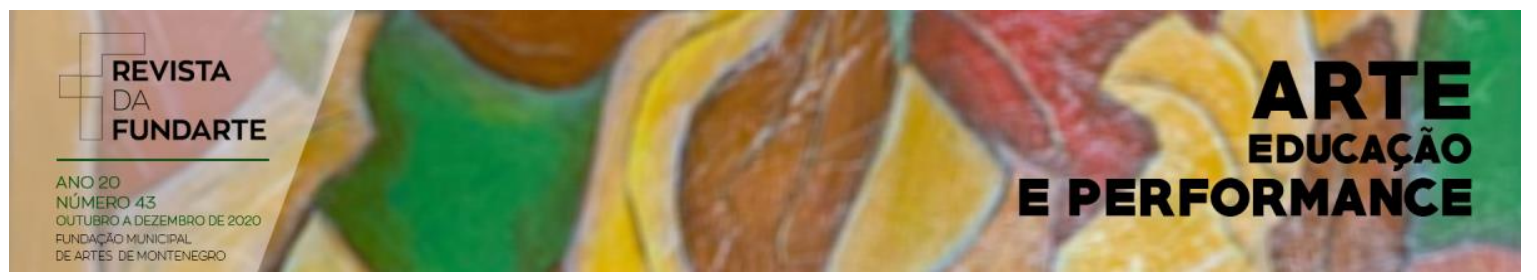

formação? Se sim, de que tipo seria, e quais os motivos atribuem a essa falta?

2. Quais noções e conceitos os estudantes atribuem à experiência e à experiência artística?

3. É possível perceber tais noções e conceitos nos modos de se articularem em seus processos de formação?

4. O que os estudantes entendem por ensino em Artes Visuais, e quais conteúdos, currículos e metodologias pensam que deveriam fazer parte de sua formação?

5. Segundo os estudantes, que tipo de contribuições um curso universitário em Artes Visuais pode oferecer para sua formação profissional?

Ao investigar estas questões, procurei trazer à tona relatos de percurso de estudantes de fases mais avançadas do curso, muitos já em fase de conclusão. Tive a preocupação de provocar a construção de pequenas cartografias ${ }^{4}$, abordando situações de escolhas, processos e vivências que deram sentido ao percurso formativo dos participantes, a fim de promover a construção de autobiografias, como prática corrente para artistas e professores, considerando a importância de olhar para si e para os próprios caminhos como estratégia para pensar a formação profissional.

Iniciei a pesquisa com um levantamento teórico/bibliográfico, a fim de localizar referenciais que tratassem do conceito de experiência no campo da educação e da produção artística, além de uma investigação a respeito do método cartográfico. Em um segundo momento, preparei a pesquisa de campo escolhendo alguns passos para proceder com as cartografias dos participantes, primeiramente, localizando estudantes em fases mais avançadas dos cursos, e que estivessem atuando como monitores em ateliês, bolsistas de projetos de extensão, agentes culturais e organizadores de projetos em ateliês e/ou oficinas de artes. Em seguida, iniciei o

\footnotetext{
${ }^{4}$ Para investigar o método cartográfico realizei pesquisas em: KASTRUP; PASSOS; ESCÓSSIA (2009).
}

NOGUEIRA, Ana Carolina Ribeiro. Experiência artística na formação docente em artes visuais: uma cartografia sobre os percursos formativos de estudantes em graduação. Revista da FUNDARTE. Montenegro, p.01-20, ano 20, № 43, outubro/dezembro de 2020.

Disponível em: http://.seer.fundarte.rs.gov.br/index.php/revistadafundarte/index> 20 de dezembro de 2020. 


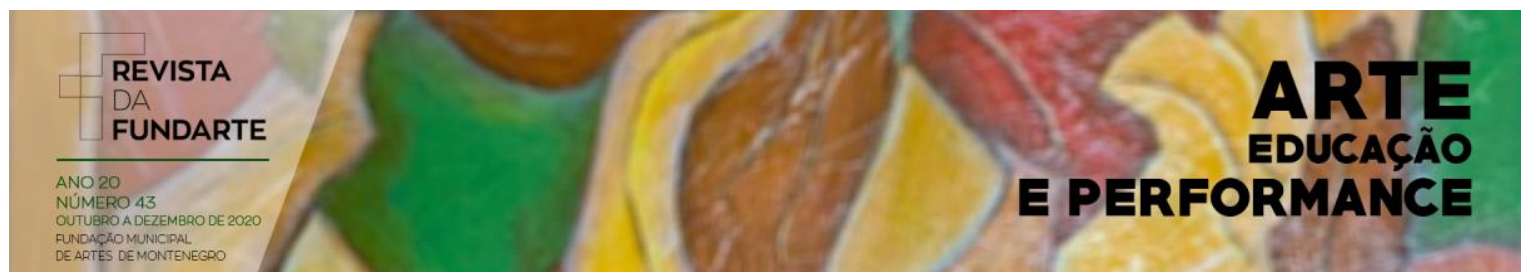

trabalho de campo, convidando cada estudante a participar de um documentário ${ }^{5}$ sobre os seus modos de produzir arte durante a graduação, e propus conversas a respeito de suas trajetórias, por meio de entrevistas semiestruturadas.

Entendo que a cartografia empregada à investigação sobre a experiência artística contribui especialmente devido às possibilidades inventivas que o método abarca, e também pelos formatos alternativos que abrem a possibilidade de reconhecimento de experiências artísticas provocadas pelo próprio processo de pesquisa. Compreendo também que se trata de um método que contribui na investigação sobre questões comuns aos estudantes e sobre o campo de formação em Artes Visuais como um todo, por nos possibilitar um acesso mais próximo a histórias, saberes e perspectivas de indivíduos comuns.

A cartografia teve importância fundamental nesta pesquisa, pois foi na construção dos 'mapas abertos' que os participantes puderam trazer suas maiores contribuições, juntando traços, passagens e memórias de todo o seu percurso, antes mesmo da formação, já que foram provocados a cartografar, inclusive, os motivos e os caminhos que os levaram a procurar pelos cursos de Artes Visuais.

Por se tratar de uma pesquisa sobre a experiência e, portanto, de um olhar para possíveis subjetivações em situações de formação e produção artística e docente, é importante dizer que esta não foi uma busca por estabelecimento de protocolos, mas sim por estudos de processos para acompanhamento de trajetórias, que podem e devem vir à tona, e para uma contribuição com a formação de novos artistas e professores, bem como para a abertura à "experiência de si" por parte dos estudantes que participaram da investigação. Para tanto, necessitava-se de um método processual, que permitisse mais a produção do que a coleta de dados, a fim de tecer uma investigação criativa que operasse e se relacionasse com os elementos históricos e materiais produzidos pelos estudantes.

\footnotetext{
${ }^{5} \mathrm{O}$ documentário, intitulado Modos de artistar na formação em Artes Visuais, encontra-se no seguinte endereço: $<$ https://www.youtube.com/watch?v=q0FW9k2jydM\&t=374s>.
}

NOGUEIRA, Ana Carolina Ribeiro. Experiência artística na formação docente em artes visuais: uma cartografia sobre os percursos formativos de estudantes em graduação. Revista da FUNDARTE. Montenegro, p.01-20, ano 20, no 43, outubro/dezembro de 2020.

Disponível em: http://.seer.fundarte.rs.gov.br/index.php/revistadafundarte/index $>20$ de dezembro de 2020. 


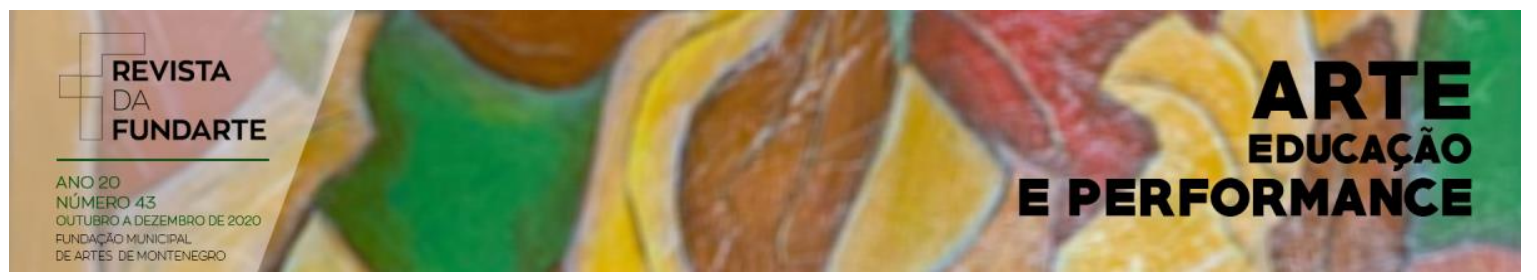

\section{Caminhos percorridos antes da universidade}

Durante a pesquisa na universidade, cursando disciplinas e atuando como monitora, conheci muitos estudantes e foi possível observar que grande parte dos ingressantes já passaram por um, dois ou até três cursos de graduação, na maior parte dos casos sem concluí-los, sendo o curso de Artes Visuais uma escolha mais consciente, após a tentativa em outras áreas geralmente afins, como os cursos de Design, Arquitetura, Engenharias e História, que são as áreas que mais aparecem.

Entre os participantes da pesquisa, cinco entre os dez entrevistados já haviam passado por experiências em outras universidades, sendo que um deles já havia concluído o curso de Design e atua profissionalmente na área. Neste caso, o estudante decidiu cursar a licenciatura após avaliar também as possibilidades de uma segunda formação profissional. Entretanto, Artes Visuais aparece como o "curso dos sonhos", uma formação mais por prazer do que necessariamente, para inserção no mercado de trabalho, já que essa etapa havia sido concluída e lhe traz os rendimentos financeiros necessários para investir na segunda formação.

Nos casos dos estudantes que desistem de outros cursos antes de concluí-los e optam por ingressar em Artes Visuais, diferentes motivos aparecem, entre os quais, especialmente por parte dos licenciandos, que argumentam que a busca pelo curso veio da vontade de transformar o ensino de Arte na escola, devido às próprias experiências negativas com esse componente curricular em seus percursos escolares.

Um dos participantes tem uma história bem distinta dos demais. Escolheu 0 curso muito antes de terminar a escola fundamental, pois era estimulado pelos professores a ser artista, já que sempre demonstrou grande interesse em arte desde criança, desenhando, pintando e esculpindo, além de grande participação em atividades que envolviam produção artística na escola.

Os casos de estudantes que escolheram as Artes Visuais logo na primeira tentativa são mais raros, sendo que, dos dez participantes, quatro alegaram essa

NOGUEIRA, Ana Carolina Ribeiro. Experiência artística na formação docente em artes visuais: uma cartografia sobre os percursos formativos de estudantes em graduação. Revista da FUNDARTE. Montenegro, p.01-20, ano 20, no 43, outubro/dezembro de 2020.

Disponível em: http://.seer.fundarte.rs.gov.br/index.php/revistadafundarte/index 20 de dezembro de 2020. 


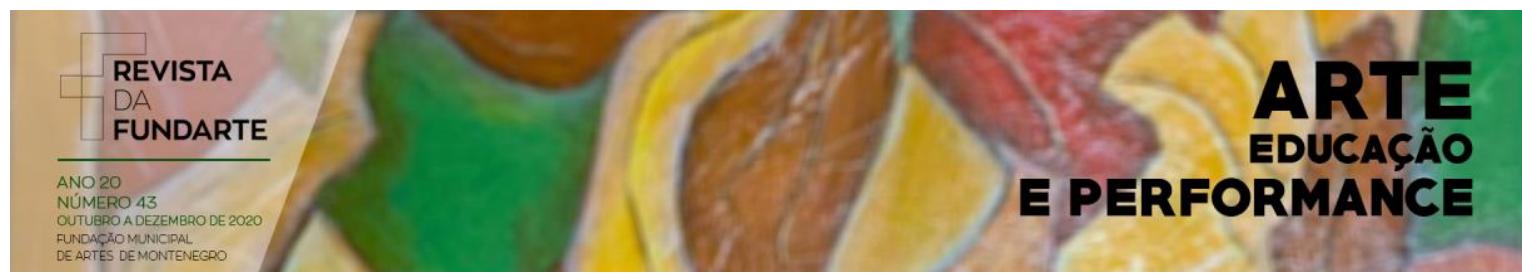

condição. Nestes casos, os graduandos decidiram por esta carreira porque sempre estiveram, de algum modo, conectados com práticas artísticas desde a infância.

Outros motivos que levam os estudantes a optar por uma segunda formação, ou interromper um curso em andamento para iniciar nas Artes Visuais, são as possibilidades de conexões interdisciplinares que as artes propiciam. Como a maioria vem de cursos nas áreas de ciências humanas, tais possibilidades de conexões são, de fato, muito amplas. Existem estudantes que se conectam as Artes Visuais depois de terem experiências com o cinema, com a performance, com a fotografia, entre outras atividades e/ou linguagens.

A seguir, poderemos ver os depoimentos de alguns estudantes a respeito de suas escolhas:

\begin{abstract}
Por que eu escolhi o curso? A história é longa... Eu vim de outros cursos. Passei por três cursos antes de entrar nas Artes Visuais. Eu acredito que aqui eu consigo fazer mais conexões com outros saberes e outras áreas de conhecimento. (Jade Sapucahy, in: MODOS de artistar na formação em Artes Visuais, 2018, entrevista).
\end{abstract}

Porque eu estava no ensino médio e via um descaso do ensino de artes, apesar de eu não saber o que um curso desses podia me oferecer. Mas as aulas eram só de desenhar palhacinho, fazer bolinha, preencher imagens... E uma vez eu questionei meu professor, se ele não ia passar mais nada além daquilo. Ali ele olhou pra minha cara e disse assim:

- Se tu queres aprender alguma coisa, faz que nem eu fiz, para numa banca de jornal e vai buscar conhecimento lá. Aí o pessoal começou a tirar sarro da minha cara.

Aí eu levantei e saí da sala, e fui falar com o diretor. Chegando lá, eu contei o caso pra ele, e ele chegou e falou com desdém:

- Você acha que arte é importante?

Aí eu saí desse colégio e fui pra outro, mas isso tudo sem saber da importância da arte... A gente nunca pensou desse jeito, a gente era de origem bem pobre. Só que isso me indignou, e eu pensei assim: Bom, eu tenho que fazer alguma coisa da minha vida. Eu gosto de dar aula. Eu sempre brinquei com meus irmãos de ser professora, e aí eu fui pesquisando, e é isso aí. Agora eu estou aqui. (Verônica Gazola, in: MODOS de artistar na formação em Artes Visuais, 2018, entrevista).

As descontinuidades entre as experiências que acontecem durante a vida são expressas nestes depoimentos, sendo esta uma das questões que me instigaram a

NOGUEIRA, Ana Carolina Ribeiro. Experiência artística na formação docente em artes visuais: uma cartografia sobre os percursos formativos de estudantes em graduação. Revista da FUNDARTE. Montenegro, p.01-20, ano 20, no 43, outubro/dezembro de 2020.

Disponível em: http://.seer.fundarte.rs.gov.br/index.php/revistadafundarte/index 20 de dezembro de 2020. 


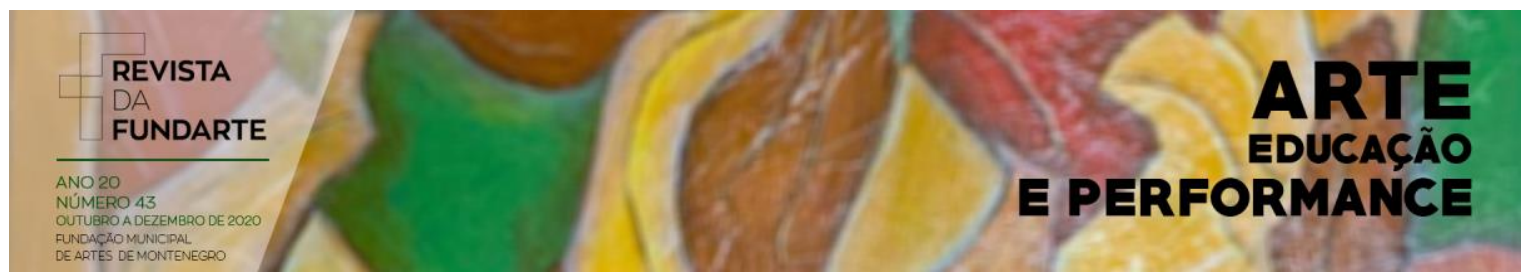

realizar a pesquisa, ou seja, saber de que modo trajetórias por vezes tão distintas do universo das artes poderia trazer estes estudantes para um curso de Artes Visuais na universidade.

John Dewey (2010) tem uma passagem que suscita reflexões a respeito das descontinuidades de nossas experiências de vida, salientando que, na maior parte do tempo, não temos controle do que nos passa, a ponto de sabermos se esta ou aquela situação ou experiência parcial, em algum momento, somará em uma experiência completa que fará um sentido maior em nossos caminhos, como no caso de uma escolha profissional, por exemplo.

A experiência ocorre continuamente, porque a interação do ser vivo com as condições ambientais está envolvida no próprio processo de viver. Nas situações de resistência e conflito, os aspectos e elementos do eu e do mundo implicados nessa interação modificam a experiência com emoções e ideias, de modo que emerge a intenção consciente. Muitas vezes, porém, a experiência vivida é incipiente. As coisas são experimentadas, mas não de modo a se comporem em uma experiência singular. Há distração e dispersão; o que observamos e o que pensamos, o que desejamos e o que obtemos, discordam entre si. Pomos as mãos no arado e viramos para trás; começamos e paramos não porque a experiência tenha atingido o fim em nome do qual foi iniciada, mas por causa de interrupções externas ou da letargia interna. (DEWEY, 2010, p. 109).

Por outro lado, podemos perceber, nas falas a seguir, que alguns estudantes optam pelo curso de Artes Visuais após terem vivenciado experiências singulares já durante a vida escolar, as quais abrem os caminhos para as tomadas de decisões mais conscientes em momentos de escolhas, como o momento da realização do vestibular.

Eu escolhi esse curso porque, desde a infância, como na escola e em casa, eu sempre tive muita aptidão pras coisas relacionadas à manualidade, a trabalhar com materiais como tinta, madeira... Então, eu sempre busquei fazer coisas que resgatassem isso... $E$ as Artes Visuais foi a alternativa. $E$ paralelamente a isso, eu tinha vontade de ser professor. (Fabio Luis, in: MODOS de artistar na formação em Artes Visuais, 2018, entrevista).

Eu optei por Artes porque é algo que está na essência do meu próprio ser,

NOGUEIRA, Ana Carolina Ribeiro. Experiência artística na formação docente em artes visuais: uma cartografia sobre os percursos formativos de estudantes em graduação. Revista da FUNDARTE. Montenegro, p.01-20, ano 20, no 43, outubro/dezembro de 2020.

Disponível em: http://.seer.fundarte.rs.gov.br/index.php/revistadafundarte/index> 20 de dezembro de 2020. 


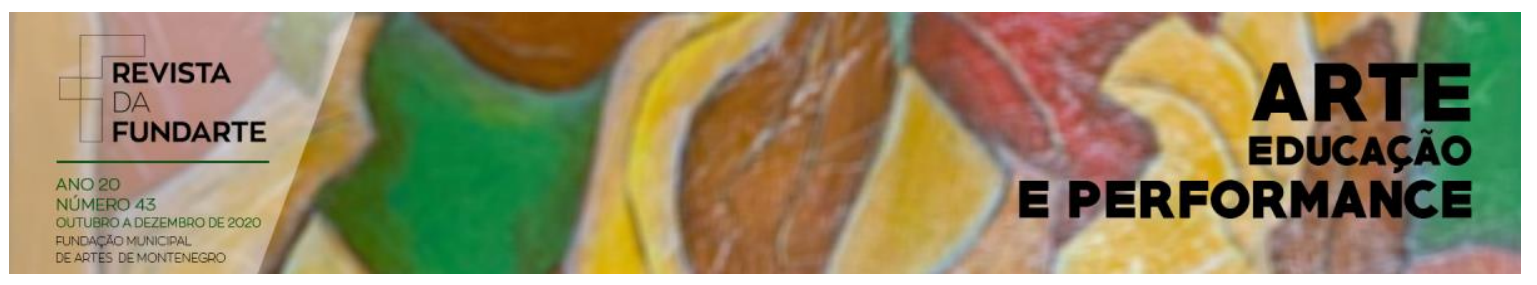

viver arte, respirar arte. Eu não me vejo fazendo outra coisa. Então, tu podes me pagar um curso de medicina, um curso de engenharia, um curso de direito, que são cursos de alto escalão na sociedade brasileira, mas eu não faria nenhum deles, nem pagando. Eu faço artes, pagaria por um curso de artes se eu tivesse condição, mas eu não tenho, e é por isso que eu estudo numa universidade pública. (Fabrício Garcia, in: MODOS de artistar na formação em Artes Visuais, 2018, entrevista).

John Dewey (2010) também contribui para pensarmos nessas experiências específicas que, somadas, passam a dar corpo para escolhas maiores. Decisões que vão implicar em uma formação profissional, como ser artista ou professor, por exemplo.

\begin{abstract}
Em contraste com essa experiência, temos uma experiência singular quando o material vivenciado faz o percurso até sua consecução. Então, e só então, ela é integrada e demarcada pelo fluxo geral da experiência proveniente de outras experiências. Conclui-se uma obra de modo satisfatório; um problema recebe sua solução; um jogo é praticado até o fim; uma situação, seja a de fazer uma refeição, jogar uma partida de xadrez, conduzir uma conversa, escrever um livro ou participar de uma campanha política, conclui-se de tal modo que seu encerramento é uma consumação, e não uma cessação. Essa experiência é um todo e carrega em si seu caráter individualizador e sua autossuficiência. Trata-se de uma experiência. (DEWEY, 2010, p. 109).
\end{abstract}

Assim, segundo Dewey, podemos pensar que há uma série de tipos de experiências que intercalam experiências incompletas e singulares; situações que foram observadas, sentidas, refletidas, e outras que passaram como um pequeno detalhe, mas que, no final das contas, acabam fazendo parte de um todo mais complexo em momentos posteriores,

[...] porque a vida não é uma marcha ou um fluxo uniforme e ininterrupto. É feita de histórias, cada qual com seu enredo, seu início e movimento para seu fim, cada qual com seu movimento rítmico particular, cada qual com sua qualidade não repetida, que a perpassa por inteiro. (DEWEY, 2010, p. 110).

Já Larrosa (2017, p. 43), em algum momento de seus escritos sobre experiência, diz que

NOGUEIRA, Ana Carolina Ribeiro. Experiência artística na formação docente em artes visuais: uma cartografia sobre os percursos formativos de estudantes em graduação. Revista da FUNDARTE. Montenegro, p.01-20, ano 20, no 43, outubro/dezembro de 2020.

Disponível em: http://.seer.fundarte.rs.gov.br/index.php/revistadafundarte/index> 20 de dezembro de 2020. 


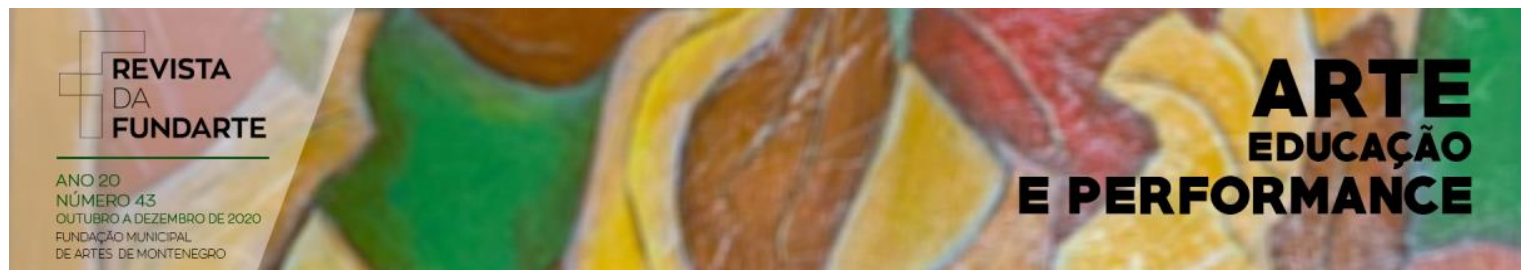

[...] a experiência é o que é, e além disso mais outra coisa, e além disso uma coisa para você e outra coisa para mim, e uma coisa hoje e outra amanhã, e outra coisa ali, e não se define por sua determinação e sim por sua indeterminação, por sua abertura.

Consideradas as distinções entre as abordagens, é interessante perceber as nuances que aparecem quando justapomos os diferentes conceitos teóricos sobre o tema da experiência e as falas dos estudantes. No caso de Larrosa (2017), também é possível pensar a experiência como acontecimento, como algo menos previsível ou determinável, mas que, no entanto, quando nos atravessa, faz com que nos submetamos à mesma.

Fazer uma experiência com algo - seja uma coisa, um ser humano, um deus - significa que algo nos acontece, nos alcança, que se apodera de nós, que nos derruba e nos transforma. Quando falamos de "fazer" uma experiência, isto não significa exatamente que nós façamos acontecer, "fazer" significa aqui: sofrer, padecer, agarrar o que nos alcança receptivamente, aceitar, na medida em que nos submetemos a isso. (LARROSA, 2017, p. 99).

Seguem algumas falas de estudantes que evidenciam essa cadência das experiências de vida, que ora parecem imprevistos, ora parecem muito bem articuladas e realizadas de forma completamente intencional.

Bom... Eu sempre fui metido. Desde que eu me conheço por gente... desde criança, eu trabalho com madeira, com pintura, com fotografia. Desde que eu comecei a pegar em câmeras, eu filmava, montava vídeos. Eu fui estudante de engenharia por muito tempo até desistir, porque eu me frustrei bastante. E aí eu decidi que ia trabalhar com Artes Visuais e com cinema. Prestei vestibular só pra Artes Visuais, passei, e agora eu estou aqui. (João Lázaro, in: MODOS de artistar na formação em Artes Visuais, 2018, entrevista).

Esta é a segunda faculdade que eu estou fazendo. Moda foi o primeiro curso. Eu escolhi o curso de Artes Visuais mais pra um complemento da outra faculdade, e pra pegar a licenciatura e poder dar aula. Eu penso em seguir carreira acadêmica, fazer mestrado e doutorado. (Dalva de Assis, in: MODOS de artistar na formação em Artes Visuais, 2018, entrevista).

NOGUEIRA, Ana Carolina Ribeiro. Experiência artística na formação docente em artes visuais: uma cartografia sobre os percursos formativos de estudantes em graduação. Revista da FUNDARTE. Montenegro, p.01-20, ano 20, no 43, outubro/dezembro de 2020.

Disponível em: http://.seer.fundarte.rs.gov.br/index.php/revistadafundarte/index> 20 de dezembro de 2020. 


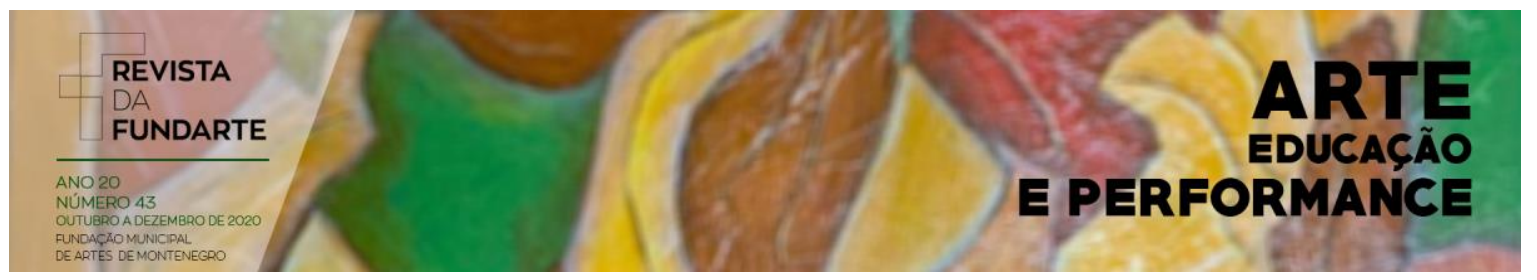

Foi porque eu gostava de desenhar muito desde pequena. Acho que isso é bastante comum, né? A gente vir pro curso por causa disso. E eu gostava bastante de História da Arte também. Mas eu acabei me desviando completamente disso que me trouxe pra cá. Eu trabalho com cerâmica. Eu trabalho com torno... Eu estudo o torno. (Ágata Tomaselli, in: MODOS de artistar na formação em Artes Visuais, 2018, entrevista).

O ingresso na universidade é um ponto-chave nas cartografias dos estudantes, pois nas suas falas foi possível encontrar particularidades sobre momentos de dúvidas e decisões; escolhas sobre determinadas práticas, desvios e recuos que dão forma às suas experiências singulares dentro do curso de Artes Visuais.

\section{As Artes Visuais como possibilidade de graduação acadêmica e carreira profissional}

Para tratar deste tema e dar continuidade à pesquisa, foi necessário partir da seguinte questão: Para ser artista e/ou professor de Artes, é necessário passar por um curso de Artes Visuais na academia? Esta é uma reflexão constante entre os estudantes, e que perpassa os assuntos da experiência e da prática artística na formação, de modo que se torna importante saber os tipos de experiências que se processam entre eles. Para isso, foi necessário falar dos seus cotidianos na universidade, de suas escolhas e desejos, para então compreender o que esperam da formação acadêmica.

Nesta altura da investigação, optei por dialogar com ideias de Célia Maria Almeida (2009), que realizou uma pesquisa sobre a experiência artística de professores de cursos superiores de Artes Visuais, na qual pude perceber pontos de encontro com meus interesses de pesquisa. A pesquisadora também adotou a cartografia como método para pensar a artisticidade dentro da academia, a partir de

NOGUEIRA, Ana Carolina Ribeiro. Experiência artística na formação docente em artes visuais: uma cartografia sobre os percursos formativos de estudantes em graduação. Revista da FUNDARTE. Montenegro, p.01-20, ano 20, no 43, outubro/dezembro de 2020.

Disponível em: http://.seer.fundarte.rs.gov.br/index.php/revistadafundarte/index> 20 de dezembro de 2020. 


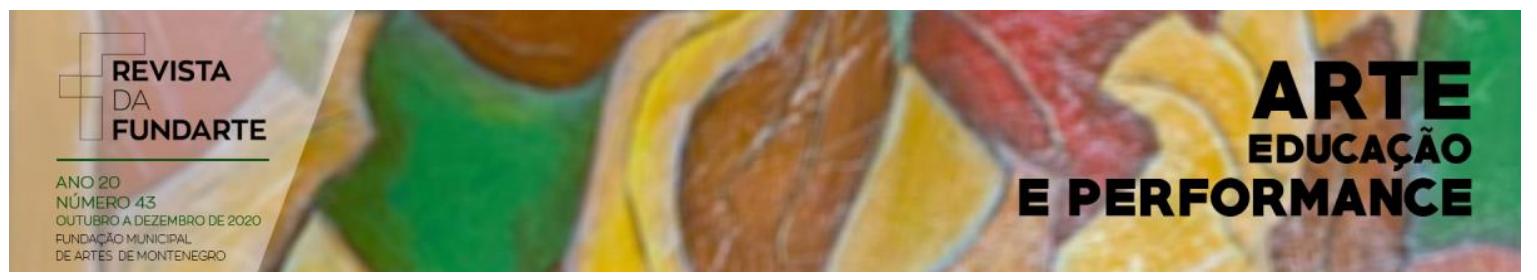

entrevistas com professores, abordando especialmente questões sobre produção artística e docência em Artes.

Optei em me aprofundar em seus estudos por se tratar de uma pesquisa que vai além dos registros documentados, e possibilita olhar de forma mais íntima para questões institucionais, que geralmente são permeadas por burocracias que tornam difícil perceber detalhes que só poderiam ser mais bem observados quando entramos em contato com subjetividades de pessoas que vivenciam, de fato, tais espaços e relações.

Deste modo, meu segundo questionamento aos estudantes foi a respeito das contribuições da universidade na constituição de suas profissões, que em alguns casos já estão acontecendo, e em outros, em vias de acontecer, para os que estão nas fases finais do curso. Para Célia de Almeida (2009, p. 23), o trabalho com experiência "requer abordagem não abstrata com foco no existir e fazer cotidianos, que acolha a subjetividade, ambiguidade e contraditoriedade. Alcançá-la requer interrogar fatos e certificar-se de que respondam com sua própria voz".

Considero que, após ter acesso a uma diversidade de histórias e conhecer os distintos motivos que trazem os estudantes até o curso, e saber das suas justificativas sobre a importância da universidade para suas vidas, pude legitimar a minha escolha por trabalhar com histórias pessoais não documentadas oficialmente, optando por um direcionamento do olhar para pequenos processos sociais, ou, como sugere Almeida (2009, p. 25), por "desdobramentos múltiplos e heterogêneos em que os sujeitos se constituem e nos quais a face real e concreta da sociedade toma forma".

Foi interessante notar, como podemos ver a seguir, que todos os participantes, de um modo ou de outro, citaram as redes de contatos pessoais ou grupos de pesquisa e extensão como principais vantagens em estar cursando uma universidade pública na área de Artes Visuais:

As conexões com as pessoas que você acaba conhecendo. Por exemplo, o

NOGUEIRA, Ana Carolina Ribeiro. Experiência artística na formação docente em artes visuais: uma cartografia sobre os percursos formativos de estudantes em graduação. Revista da FUNDARTE. Montenegro, p.01-20, ano 20, ㄲo 43, outubro/dezembro de 2020.

Disponível em: http://.seer.fundarte.rs.gov.br/index.php/revistadafundarte/index> 20 de dezembro de 2020. 


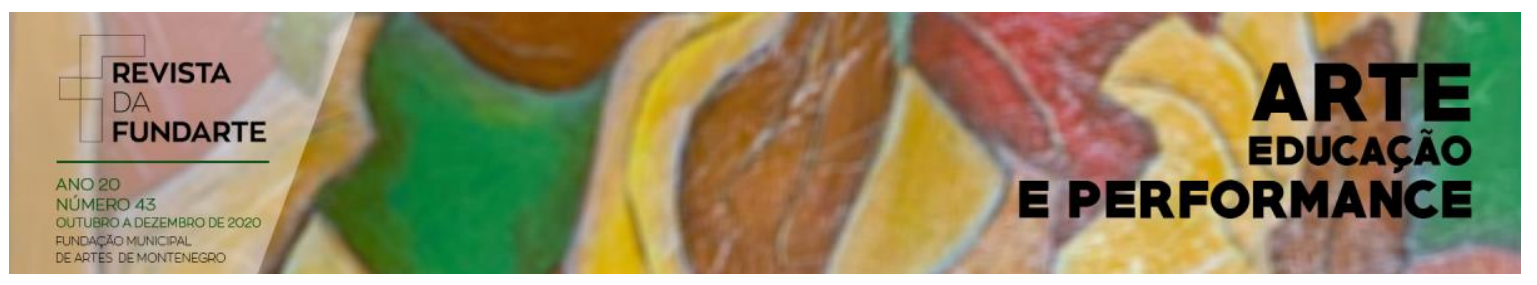

coletivo, Geodésica Cultural Itinerante, que eu conheci. A primeira professora que me dava aula de torno na Escola de Oleiros, que se voluntariou pra dar aula aqui, e foi onde eu comecei a estudar o torno.

Então, eu acho que são as pessoas. É claro que tem os conhecimentos também, o acesso aos materiais, que em outros lugares você não tem. Que nem aqui na UDESC tem o torno, o forno, que são coisas caras. Tem todo um espaço também, né? Mas conhecer pessoas que estão fazendo coisas próximas a você, e às vezes muito diferentes, mas que agregam pra você, eu acho que é uma das coisas mais importantes da universidade (Ágata Tomaselli, in: MODOS de artistar na formação em Artes Visuais, 2018, entrevista).

A experiência na universidade como um todo foi importantíssima, porque as oportunidades que eu tive de participar de ações de extensão, poder entrar em contato com as oficinas de audiovisual, que me ensinaram as coisas que eu sei, de fato, elas são responsáveis pela minha formação. É claro que, falando isso, parece que eu aproveitei pouca coisa da universidade, o que é verdade mesmo. Eu acho que a universidade foi um lugar em que eu tive que vir, e, por acaso, eu conheci algumas pessoas que me ensinaram coisas, inclusive os professores. Eu considero a experiência da universidade mais como uma formação de cidadania (João Lázaro, in: MODOS de artistar na formação em Artes Visuais, 2018, entrevista).

A importância dada às redes de relações manifesta-se paralelamente às ideias da relativização da necessidade da formação acadêmica para a profissão de artista, aparentando certa relação com as considerações de Almeida (2009, p. 140) em sua pesquisa:

Para um artista, vale mais a aprendizagem informal de uma experiência própria (a interação com outros produtores de arte e o embeber-se da produção artística e da própria vida) do que um curso de pós-graduação, que reúne certas disciplinas teóricas, obrigatórias. Eles até reconhecem que elas contribuem para esclarecer mais o fazer artístico, mas dizem que não bastam e, algumas vezes, entravam seu trabalho, porque dispersam certos objetivos.

Confirmando a heterogeneidade de perspectivas, seguimos com 0 depoimento de um estudante que coloca lado a lado uma contribuição e um problema da universidade, primeiro sobre a importância das relações pessoais no curso de Artes, e depois, a forma como se organiza a questão da formação técnica para os bacharelandos.

NOGUEIRA, Ana Carolina Ribeiro. Experiência artística na formação docente em artes visuais: uma cartografia sobre os percursos formativos de estudantes em graduação. Revista da FUNDARTE. Montenegro, p.01-20, ano 20, no 43, outubro/dezembro de 2020.

Disponível em: http://.seer.fundarte.rs.gov.br/index.php/revistadafundarte/index 20 de dezembro de 2020. 


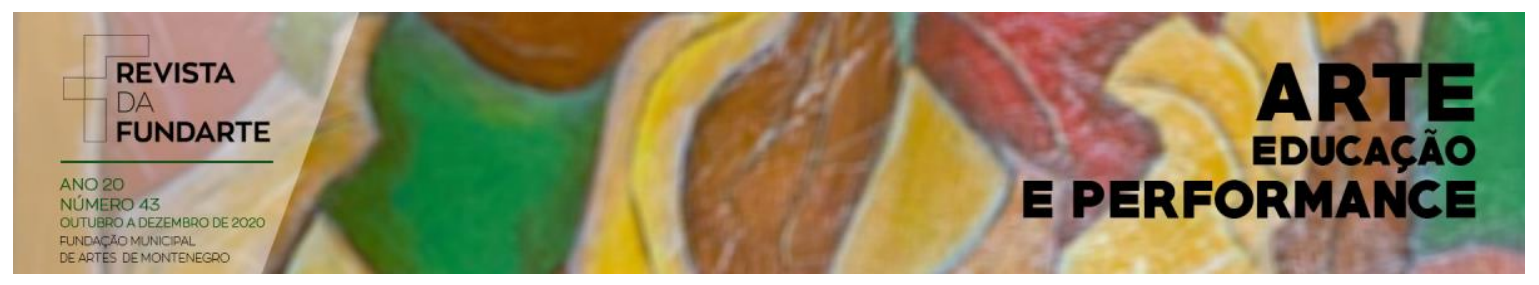

Pra mim, além de aprender algumas coisas novas, o grande ganho foi conhecer pessoas. Conhecer professores, artistas, amigos, e esse tipo de laço nenhuma faculdade a distância consegue suprir.

No entanto, eu vejo falhas principalmente no curso de bacharel, porque é um curso que não supre a necessidade de conhecimento técnico. Eu falo disso porque eu gosto muito da questão da técnica. Muitas pessoas vão contra esse meu pensamento e acham que eu sou muito tecnicista, mas eu penso assim: Se você quer uma faculdade que só te induz a falar sobre, então faça Letras, Literatura, faça Filosofia. Quer aprender a falar, Filosofia é lindo, é belo... Mas se tu queres aprender a pintar, aprenda a pintar, aprenda a parte técnica. Quer conceituar 'em cima'? Melhor ainda. Mas falta isso, entendeu? Falta essa ligação entre técnica e conceito, porque ficou só no conceito. Daí as pessoas retornam pra licenciatura (que é a grande parte dos casos) porque querem trabalhar. Então acho que é assim: muito se deixa de lado a questão técnica, por achar que é uma questão muito frágil. Eu não acho, porque, se ao menos você tem uma situação de conhecimento, de criação, você pode, pelo menos, adentrar no mercado de trabalho. Agora, se o bacharelado não serve nem pra isso, pra criar pessoas capacitadas pra um mercado de trabalho, pra que serve o bacharel? Pra colar diploma na parede?

Agora, a licenciatura eu acho de extremo fundamento existir. Agora existe muito essa briga, entre bacharelado e licenciatura. $O$ que é o artista, professor que quer ser artista... (Fabrício Garcia, in: MODOS de artistar na formação em Artes Visuais, 2018, entrevista).

É possível perceber que a reivindicação e a preocupação com as questões da técnica e da prática artística, assim como na pesquisa de Almeida (2009, p. 65), também demonstram uma tentativa dos estudantes em resguardar a profissão do artista, estando "em jogo o 'ser artista', ou seja, sua angústia na busca de soluções que evitem o apagamento da especificidade de seu trabalho nas regras e normas da instituição".

As questões da técnica, das oportunidades de acesso a conhecimentos práticos e teóricos nunca antes acessados, e a habilitação para as questões pedagógicas no ensino das Artes Visuais, também foram pontos em comum entre todos os participantes.

As minhas experiências aqui estão sendo boas pra mim, sabe? Porque eu não conhecia nada além daqui. Tudo que eu estou vendo de arte está sendo aqui, e eu estou aproveitando ao máximo sabe? A universidade fornece as coisas. Só que só vai faltar dependendo do interesse do aluno.

NOGUEIRA, Ana Carolina Ribeiro. Experiência artística na formação docente em artes visuais: uma cartografia sobre os percursos formativos de estudantes em graduação. Revista da FUNDARTE. Montenegro, p.01-20, ano 20, no 43, outubro/dezembro de 2020.

Disponível em: http://.seer.fundarte.rs.gov.br/index.php/revistadafundarte/index> 20 de dezembro de 2020. 


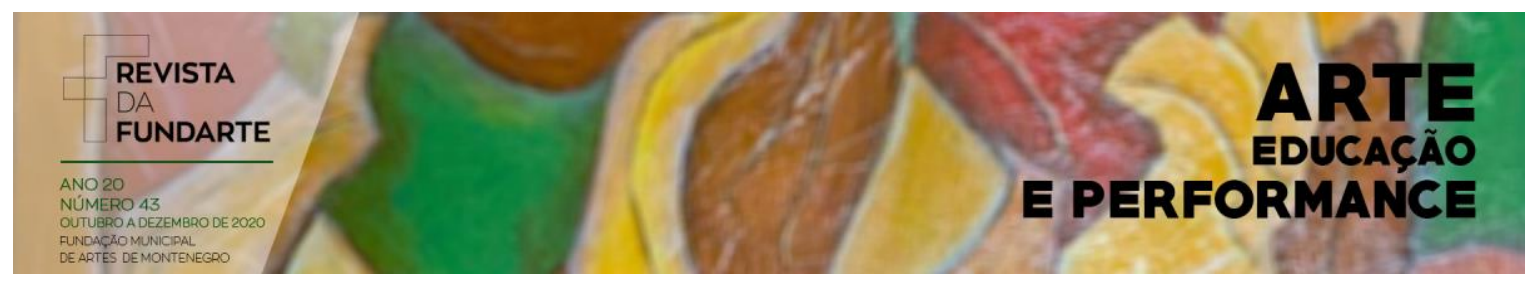

Por exemplo, pra área de fotografia falta muito pra mim. Antes de entrar aqui eu pesquisei porque era a área que eu mais conhecia. Aí eu consultei a ementa da disciplina, e vim achando que eu ia aprender processos artísticos, história da fotografia... Só que aí faltou coisa pra caramba. Eu tive que buscar bastante coisa fora. Eu até fui conversar com o professor, e ele me passou bastante coisa. Só que assim, eu tive que ir lá ver outras formas de aprender. Então, a universidade me deu uma base, mas eu que tive que aprofundar fora daqui.

Tem coisas que eu estou vendo aqui que eu nunca tinha visto. Como eu te falei, venho de uma escola sem nenhuma estrutura e que não dava importância nenhuma pra arte. Então, eu só sabia o que era pintar; eu não sabia a diferença entre pintar e desenhar. Eu fui aprender isso tudo aqui. Então, por mais que sejam coisas muito sutis, pra mim faz toda a diferença, sabe? Eu valorizo muito estar aqui. (Verônica Gazola, in: MODOS de artistar na formação em Artes Visuais, 2018, entrevista).

Foi útil em muitos sentidos. A teoria em si, que é legal ter, é importante pra vida... Ter um conhecimento sobre História da Arte, pra saber sobre desenho, pra fazer um jogo, um filme... Então, ter uma noção de História é fundamental, na minha opinião. Foi importante pra conhecer técnicas variadas, por a gente ter uma certa experimentação em gravura, pintura. Porque eu não sabia o que era uma gravura antes. Não sabia como se trabalhar uma escultura, sobre os moldes. Então, isso tudo ampliou o leque de possibilidades. (lan Bruscky, in: MODOS de artistar na formação em Artes Visuais, 2018, entrevista).

Como foi comentado anteriormente, meu interesse de pesquisa foi conhecer estudantes que, de uma forma ou de outra, estavam conectados com o ensino de Artes, mesmo cursando o bacharelado. Deste modo, foi possível perceber que todos os participantes tinham certa clareza sobre suas escolhas e, assim como na pesquisa de Almeida (2009), todos escolheram o caminho do ensino, paralelamente ao da produção artística, pois perceberam uma grande conexão entre as duas profissões, por terem grandes afinidades com questões do campo pedagógico, bem como por compreenderem a arte como atividade coletiva e a prática pedagógica como experiência artística.

Em sua investigação com os professores de instituições de ensino superior em Artes Visuais, Almeida (2009, p. 71) averiguou que:

Se pode depreender que "optar" pela docência como carreira paralela à de artista resulta da convicção de que o ensino, mais do que qualquer outra

NOGUEIRA, Ana Carolina Ribeiro. Experiência artística na formação docente em artes visuais: uma cartografia sobre os percursos formativos de estudantes em graduação. Revista da FUNDARTE. Montenegro, p.01-20, ano 20, no 43, outubro/dezembro de 2020.

Disponível em: http://.seer.fundarte.rs.gov.br/index.php/revistadafundarte/index 20 de dezembro de 2020. 


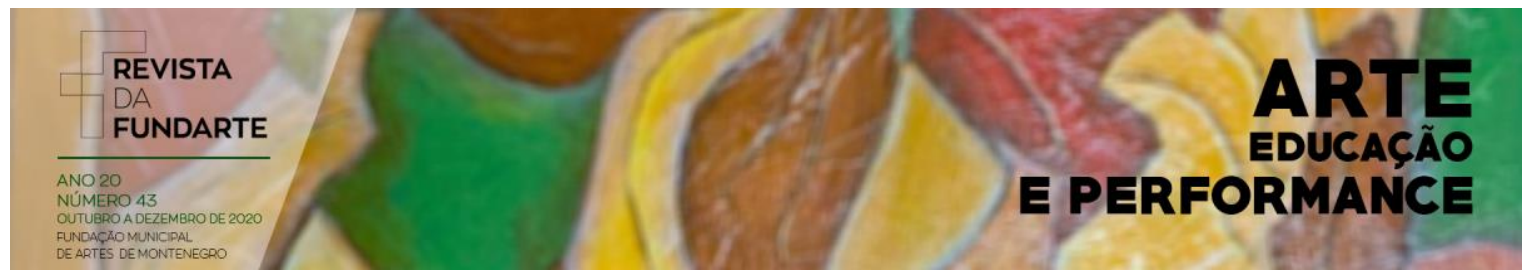

profissão, é conciliável com a produção artística. Mais que isso, o ensino, dentre as inúmeras possibilidades de trabalho, é aquela com que mais se identificam.

Podemos refletir sobre tais escolhas a partir das seguintes falas dos estudantes:

Bom, pra ser artista você não precisa necessariamente estar numa universidade. $\mathrm{O}$ que sempre pegou pra mim era a questão da formação em licenciatura. Tinha também a questão técnica, de aprender algumas técnicas, como a gravura, que foi uma técnica que eu conheci na universidade. Sempre achei que gravura fossem ilustrações de livros. Então, eu sempre esperei e ainda espero da universidade contato com técnicas e a formação teórica, que foi o que eu consegui até então. É uma questão de instrumentalização de um fazer, de um fazer mais consciente. $E$ um pensamento mais crítico sobre a teoria do ensino, né? (Fabio Luis, in: MODOS de artistar na formação em Artes Visuais, 2018, entrevista).

A universidade foi a ponte que eu precisava pra me tornar, de fato, uma professora. Eu não teria essa consciência que eu tenho hoje, se não tivesse passado esses quatro anos no banco da academia. Por mais que as pessoas critiquem esse jeito acadêmico de ensinar, eu ainda confio nessa estratégia pedagógica antiga da universidade. (Dalva de Assis, in: MODOS de artistar na formação em Artes Visuais, 2018, entrevista).

Eu acho que o que a universidade traz é essa forma de você conseguir flexionar o seu pensamento com outros pensamentos existentes e ver 'no que dá'. Eu descobri todo um outro mundo quando eu comecei a estudar, principalmente as disciplinas da licenciatura, e comecei a perceber esse entendimento das Artes Visuais sob outra ótica. Então, eu acabei me envolvendo muito com as disciplinas da licenciatura. (Miguel Vassali, in: MODOS de artistar na formação em Artes Visuais, 2018, entrevista).

\section{Considerações finais}

Por meio deste trabalho foi possível conhecer alguns modos e possibilidades de experienciar a formação de estudantes em processo de graduação, suas formas de atuação e as maneiras como constituem suas experiências dentro das estruturas formativas, construindo grande parte de suas subjetividades artísticas no âmbito do

NOGUEIRA, Ana Carolina Ribeiro. Experiência artística na formação docente em artes visuais: uma cartografia sobre os percursos formativos de estudantes em graduação. Revista da FUNDARTE. Montenegro, p.01-20, ano 20, no 43, outubro/dezembro de 2020.

Disponível em: http://.seer.fundarte.rs.gov.br/index.php/revistadafundarte/index> 20 de dezembro de 2020. 


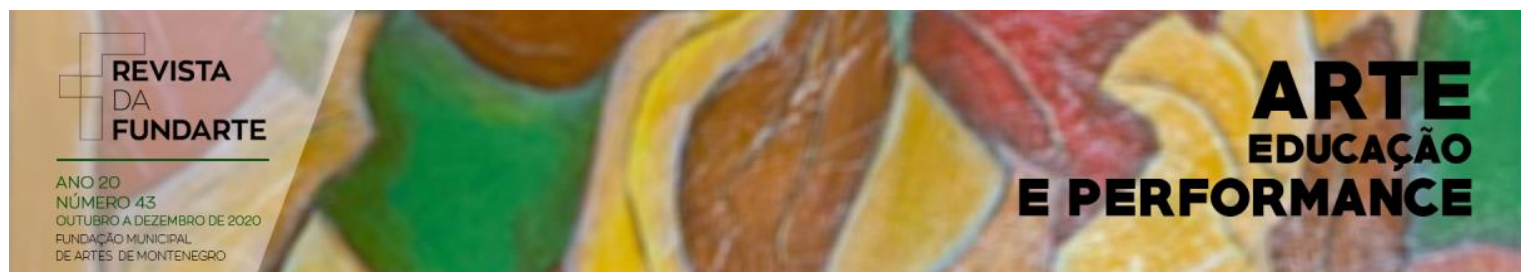

ensino/aprendizagem de Artes Visuais em uma universidade pública.

O objetivo foi tornar visíveis as condições que possibilitam tipos particulares de experiências durante o processo formativo, refletindo não apenas sobre as formas como os sujeitos realizam suas práticas artísticas durante o curso, mas principalmente sobre suas experiências como um todo, provocando-os a pensar sobre os próprios caminhos e escolhas em suas vivências de formação. Tratou-se de trazer à tona a maneira como cada sujeito experimenta e experiencia a si mesmo, considerando uma série de relações institucionais, sistemas organizados burocraticamente, e em meio a discursos oficializados que fazem parte de um campo específico.

A experiência de olhar e refletir sobre si mesmo, sobre os próprios modos de artistar e construir o processo de formação foi nossa maior preocupação nesta investigação, o que justifica a escolha por um método cartográfico, a partir do qual imaginei ser possível trazer à tona relatos de experiências subjetivas durante os processos de graduação.

Vale também justificar que, devido ao fato da pesquisa ter foco no "sujeito da experiência", optei por não esmiuçar a fundo documentos institucionais e parâmetros curriculares, para melhor me ater às dimensões subjetivas dos formandos. Esta opção por não me embrenhar nos documentos normativos encontra amparo em Almeida (2009), que entende os documentos oficiais como um tipo de mito que dissimula a realidade, que poderia ser mais bem compreendida por meio de contatos mais diretos com os sujeitos da pesquisa:

Queria saber o que está além do registro documentado por entender que os documentos mascaram o movimento real: transformam-no em algo abstrato, formal e hegemônico; falam do discurso do poder, que define sentido, finalidade, forma e conteúdo do ensino [...]. (ALMEIDA, 2009, p. 22).

E segue:

[...] ocultando o sentido real de práticas e saberes do cotidiano, enquanto o

NOGUEIRA, Ana Carolina Ribeiro. Experiência artística na formação docente em artes visuais: uma cartografia sobre os percursos formativos de estudantes em graduação. Revista da FUNDARTE. Montenegro, p.01-20, ano 20, no 43, outubro/dezembro de 2020.

Disponível em: http://.seer.fundarte.rs.gov.br/index.php/revistadafundarte/index> 20 de dezembro de 2020. 


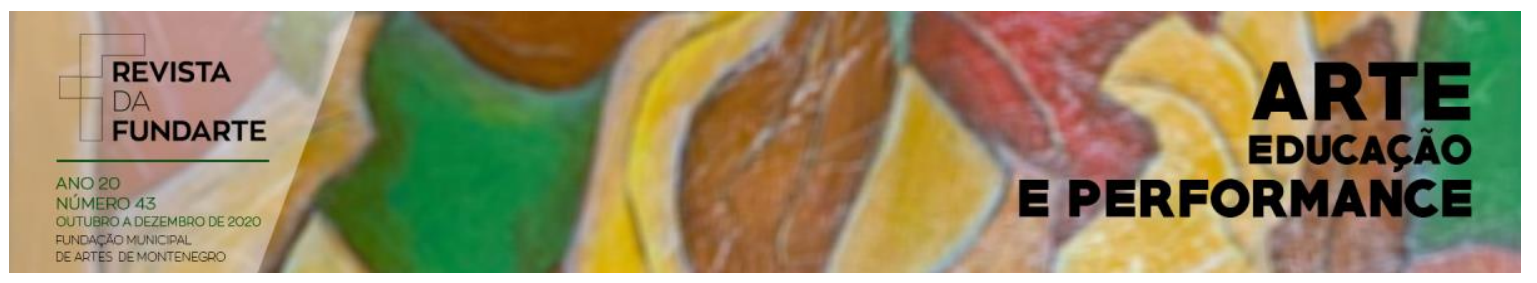

ensino não documentado é vivo, real. Numa palavra, queria discutir a concretude de um trabalho feito por quem é artista e professor; ouvir a voz dessas pessoas: saber não só o que pensam sobre ensinar arte, mas também como ensinam e como se sentem ao fazê-lo, o que pretendem e que relações estabelecem com as instituições onde trabalham. (Ibid., p. 23).

A relevância desta pesquisa encontrou-se na perspectiva de contribuir com o campo de formação em Artes Visuais ao propor reflexões sobre a experiência artística em seus aspectos expressivos e conceituais no decorrer da formação de alguns estudantes, com base nos sentidos produzidos por esses sujeitos, a partir de suas imersões nesta investigação. Isso contribuiu, na medida em que ajudou a reconhecer pontos positivos e negativos do curso de graduação em Artes Visuais da Universidade do Estado de Santa Catarina, sugerindo possibilidades de transformações, pensadas pelos próprios estudantes em formação.

\section{Referências:}

ALMEIDA, Célia Maria de Castro. Ser artista, ser professor: razões e paixões do ofício. São Paulo: Editora da Unesp, 2009. 168 pp.

CORAZZA, Sandra Mara. Artistagens: filosofia da diferença e educação. Belo Horizonte. Autêntica, 2006.

DEWEY, John. Arte como Experiência. São Paulo: Martins Fontes, 2010.

KASTRUP, Virginia; PASSOS, Eduardo; ESCÓSSIA, Liliana. Pistas do método da cartografia: pesquisa-intervenção e produção de subjetividade. Porto Alegre: Sulina, 2009.

LARROSA, Jorge. Tremores: escritos sobre experiência. Belo Horizonte: Autêntica, 2017. (Coleção Experiência e Sentido).

MODOS de artistar na formação em Artes Visuais. 2018. (50m20s). Disponível em: $<$ https://www.youtube.com/watch?v=q0FW9k2jydM\&t=374s>. Acesso em: 15 nov. 2018.

NOGUEIRA, Ana Carolina Ribeiro. Experiência artística na formação docente em artes visuais: uma cartografia sobre os percursos formativos de estudantes em graduação. Revista da FUNDARTE. Montenegro, p.01-20, ano 20, no 43, outubro/dezembro de 2020.

Disponível em: http://.seer.fundarte.rs.gov.br/index.php/revistadafundarte/index> 20 de dezembro de 2020. 